\title{
Risk Aversion, Transparency, and Market Performance
}

\author{
M. ÁNGELES DE FRUTOS and CAROLINA MANZANO*
}

\begin{abstract}
Using a model of market making with inventories based on Biais (1993), we find that investors obtain more favorable execution prices, and they hence invest more, when markets are fragmented. In our model, risk-averse dealers use less aggressive price strategies in more transparent markets (centralized) because quote dissemination alleviates uncertainty about the prices quoted by other dealers and, hence, reduces the need to compete aggressively for order flow. Further, we show that the move toward greater transparency (centralization) may have detrimental effects on liquidity and welfare.
\end{abstract}

STOCK EXCHANGES EVERYWHERE ARE ENGAGED in a contest for economies of scale and scope. In May 2000, the London Stock Exchange and the Deutsche Bourse announced a merger, along with a joint venture with America's Nasdaq, an agreement that eventually came apart. One of the main obstacles to the merger had been a lack of consensus on trading-system design and regulation.

In the design of securities-trading systems, the question of transparency has become a major issue. Regulators disagree among themselves about the desired level of transparency in stock exchange dealings. In the United States, the Securities and Exchange Commission's (SEC) view is straightforward: "The Commission has long believed that transparency-the real time, public dissemination of trade and quotation information-plays a fundamental role in the fairness and efficiency of the secondary markets ... transparency helps to link dispersed markets and improves the price discovery, fairness, competitiveness and attractiveness of U.S. markets" (Securities and Exchange Commission (1995a), Chapter IV-1). In the same vein, the SEC also argued "... transparent disclosure of quotes and trades promotes best execution" (Securities and Exchange Commission (1995b), p. 2). In contrast, in the United Kingdom, the Securities and Investment Board (SIB) has argued that there are important differences between quotation transparency and

* de Frutos is from the Department of Economics, Universidad Carlos III de Madrid, and Manzano is from the Department of Economics, Universitat Rovira i Virgili. We thank Jordi Caballé, Michael Manove, Lambros Pechlivanos, Ignacio Peña and Mikel Tapia for helpful comments. Valuable suggestions by the editor and the referee have substantially improved the paper. Financial support of grant BEC2000-0173 for the first author, and grant DGES PB970084 for the second author, is gratefully acknowledged. 
trade transparency, and that transparency (in the context of prompt publication of large trades) should be restricted if it is necessary to assure adequate liquidity. ${ }^{1}$

Transparency has two different dimensions. Pretrade transparency refers to the wide dissemination of price quotations and orders before the trade, whereas posttrade transparency refers to the public and timely transmission of information on past trades, including execution time, volume, and price. In this paper, we are primarily concerned with pretrade transparency in the form of price-quotation dissemination. Using a model of market making with inventories, ${ }^{2}$ we address the effects of pretrade transparency by comparing centralized and fragmented markets. These two kinds of market structures differ in the amount of information on price quotations that is available to dealers. In centralized markets, bid and ask prices are public. Thus, dealers can observe the quotes of their competitors. In fragmented markets, deals are often the outcome of bilateral transactions negotiated on the phone, at prices within the screen quotations. Dealers can then only hypothesize on the probability that their quotations are more attractive than those of their competitors. Examples of centralized markets are stock and futures exchanges, markets such as the Paris Bourse, or CBOT. Telephone-mediated dealer markets and the Treasury bond markets are fragmented.

Our main result is that transparency may not enhance market competitiveness. The key to understanding this surprising result is to see that market makers have a strong interest in being able to forecast their transactions, because good forecasts will lower carrying costs. Quotation visibility simplifies the dealers' task of obtaining their planned order flow, because it provides dealers with information that enables them to outbid competitors by small margins when they need more orders. If quotation visibility is lacking, dealers are uncertain about the bid required to obtain an order, and this causes them to bid more aggressively when more orders are needed. For this reason, in our model, investors obtain more favorable execution prices when markets are fragmented.

Auction theory is useful for analyzing this process. The desire to reduce inventory carrying costs causes market makers to behave as risk-averse bidders for the business of the investing public, with their price offers playing the role of the bids in an auction. In a transparent securities market, the market makers are, in effect, participating in a multiple-round open-bid (English) auction, in which each market maker always has the opportunity of surpassing the bids of competing market makers. In a fragmented market, the market makers are participating in a sealed-bid auction, with the investor opening the envelopes and choosing the winner.

\footnotetext{
${ }^{1}$ For further discussions on these issues, see Bloomfield and O'Hara (1999).

${ }^{2}$ In this setting, the market spread reflects the inventory costs dealers face in providing liquidity services. Empirical research that supports inventory models in dealer markets include Fleming and Remolona (1999) for the U.S. Treasury Market and Hansch, Naik, and Viswanathan (1998) for the London Stock Exchange.
} 
In a multiple-round open-bid auction, the bidder's dominant strategy is to continue to improve his bids either until his competitors drop out, or until the bidding of his competitors reduces his own net value of winning to zero. Risk aversion can have no effect on this strategy, because the bidder makes the decision to stop bidding with full information. However, risk aversion does have an impact on bidding strategies in a sealed-bid auction. More aggressive bids increase the probability of winning and decrease the size of the profits earned by winning: Precisely what a risk-averse bidder wants to do. This is the reason why with risk-averse bidders who have certain knowledge of their private value of winning, a sealed-bid auction can be expected to earn more for the auctioneer than a multiple-round open-bid auction. So it is with fragmented and centralized securities markets: The former earns more for the investor.

Since the public will learn to expect better execution prices in fragmented markets, the optimal market order will be larger in these markets. The implication for the optimal design of financial markets is clear: Liquidity may be enhanced when markets are less transparent. More importantly, quotation transparency need not be beneficial either for investors or for dealers. Investors' orders are executed at better prices in fragmented markets. Dealers in fragmented markets face more competition and tighter margins, but they can also enjoy lower inventory carrying costs. This welfare implication represents a departure from the standard theoretical models that omit inventory costs altogether, and helps explain why dealers have been among the most active participants in transparency discussions (see Gemmill (1996)). These welfare results have the same flavor as the results from laboratory experiments reported in Bloomfield and O'Hara (1999).

The remainder of the paper is as follows. Section I presents the model. In Section II, reservation quotes and optimal quotes are examined. Section III is devoted to the benchmark case in which the market order is determined exogenously. In Section IV, the market order of the public is determined endogenously. Section V discusses the robustness of the results. Section VI outlines the policy implications of our findings and concludes. Finally, all the proofs are relegated to the Appendix.

\section{The Model}

The model is based on the dealer market model of Biais (1993). A risky asset is traded against a riskless asset whose payoff is normalized to one. There are two types of market participants: (a) those who demand liquidity and (b) those who supply liquidity. Liquidity is demanded by outside riskaverse investors who are affected by liquidity shocks. From now on, we refer to the representative investor as the public. Liquidity is supplied by risk-averse agents, who set prices at which they will buy or sell any quantity of the risky asset. We refer to them as market makers or dealers, indistinctly. 
All the market participants, the dealers, and the public, will have CARA utility functions in their terminal wealth, with a common risk aversion coefficient $R$, that is,

$$
U(W)=-e^{-R W}
$$

Trade occurs according to the following sequence of events.

\section{A. Stage 1: Determination of $N$}

Initially, there is a population of potential liquidity suppliers, indexed by $i$. $N$ out of these agents decide to become liquidity suppliers, at a fixed cost $C$.

\section{B. Stage 2: Endowments}

Agent $i$ is endowed with cash, $T_{i}$, and with a random inventory position of the risky asset, $I_{i}$. We assume that inventories are independently and identically distributed. The cumulative distribution function of $I_{i}, F(\cdot)$, is defined on $[-M, M] .^{3}$ It is assumed that $F$ is differentiable with probability distribution function $f(\cdot)$.

Throughout the paper, we will use order statistics. Those associated with a sample of $N$ random inventory draws from $F(\cdot)$ will be denoted by $\left(I_{j}^{*}\right)_{j=1, \ldots, N}$. Thus, $I_{N}^{*}$ denotes the maximum out of $N$ random inventory draws, $I_{N-1}^{*}$ refers to the second largest inventory draw, and so on. Similarly, the order statistics associated with a sample of $N-1$ draws will be denoted by $\left(Y_{j}\right)_{j=1, \ldots, N-1}$.

\section{Stage 3: The Market Order}

With probability $\lambda$, a liquidity shock occurs. If it occurs, then the public is, equally likely, endowed with either a long position, $+L$, or a short position, $-L$, of the risky asset. At this stage, the public decides whether to buy or to sell, and the size of her market order, denoted by $Q$.

To ensure trading between the public and the dealers, it is assumed that their inventory positions are sufficiently different to generate trade. This fact is reflected in the following hypothesis: $L>M^{4}{ }^{4}$

\section{Stage 4: Trading}

Agent $i$ supplies liquidity to the public by posting a selling and a buying price, denoted by $A_{i}$ and $B_{i}$, respectively. Since all market participants have homogeneous expectations about the final value of the risky security, $A_{i}$ and

\footnotetext{
${ }^{3}$ The limitations imposed on the dealers' ability to take long and short positions are consistent with the observed limitations resulting from capital requirements or from administrative rules.

${ }^{4}$ It is important to point out that in this model there is no interdealer trading. We assume that inventory divergences among dealers are not large enough to generate profitable trades between them.
} 
$B_{i}$ can be expressed as $A_{i}=E(P)\left(1+a_{i}\right)$ and $B_{i}=E(P)\left(1-b_{i}\right)$, where $E(P)$ represents the expected final value of the risky asset and $a_{i}\left(b_{i}\right)$ represents the selling (buying) premium of dealer $i$. For simplicity, $E(P)$ is normalized to one.

Dealers' price strategies are functions of their inventory positions. Since we will focus on symmetric equilibria, the selling and buying premia of dealer $i$ are $a_{i}=a\left(I_{i}\right)$ and $b_{i}=b\left(I_{i}\right)$. These premia must satisfy the following condition: Given that $i$ 's competitors use the price strategies $a(\cdot)$ and $b(\cdot)$, dealer $i$ maximizes his expected utility by choosing $a\left(I_{i}\right)$ and $b\left(I_{i}\right)$ as his selling and buying premia.

\section{E. Stage 5: The Final Value of the Asset}

The final value of the risky asset, $P(P=1+z$, where $z$ is normally distributed with zero mean and variance $\sigma^{2}$ ), is realized.

Finally, the dealers' inventory positions, the liquidity shock and the final value of the risky asset are assumed independent random variables. The joint distribution of all these random variables will be common knowledge.

Figure 1 summarizes the sequence of events in the trading process. ${ }^{5}$

\section{Reservation Quotes and Optimal Quotes}

\section{A. Reservation Quotes}

Reservation quotes are such that dealers are indifferent between trading once at these prices and not trading. Thus, market maker $i$ chooses his reservation prices so that the expected utility of his terminal wealth from trading at those prices (i.e., from selling at an ask price $1+a_{r, i}$ or from buying at a bid price $1-b_{r, i}$ ) is equal to that if he did not trade at all. Bearing this condition in mind, the first lemma characterizes the reservation quotes.

Lemma 1: (Ho and Stoll (1983)). The reservation selling and buying prices of dealer $i$ are $1+a_{r, i}$ and $1-b_{r, i}$, where

$$
\begin{aligned}
& a_{r, i}=a_{r}\left(I_{i}\right)=\frac{R \sigma^{2}}{2}\left(Q-2 I_{i}\right), \quad \text { and } \\
& b_{r, i}=b_{r}\left(I_{i}\right)=\frac{R \sigma^{2}}{2}\left(Q+2 I_{i}\right) .
\end{aligned}
$$

\footnotetext{
${ }^{5}$ The trading game is a sequential game of incomplete information. We hence search for the standard equilibrium concept for these types of games, that is, a perfect Bayesian-Nash equilibrium.
} 


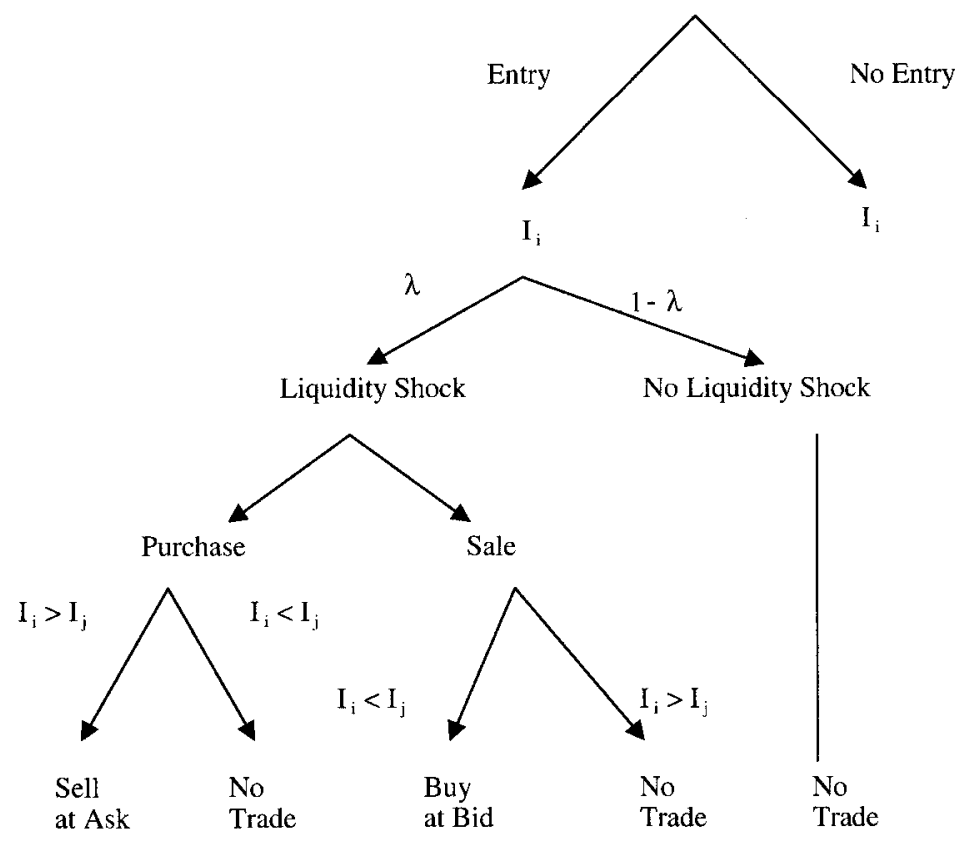

Figure 1. The trading game of agent $i$. The agent first decides whether to enter the market or not. He then receives his endowment of the risky asset, $I_{i}$. If the public is not affected by a liquidity shock, there is no trade. If there is a liquidity shock, dealer $i$ serves the market order to buy (sell) if his inventory is larger (smaller) than those of his competitors.

A reservation fee represents the cost to a dealer of participating in a transaction that makes his overall portfolio nonoptimal and/or moves him to a less desirable level of risk. ${ }^{6}$ Notice that $a_{r}\left(b_{r}\right)$ is decreasing (increasing) in the inventory position. Thus, the larger a dealer's inventory position, the greater (smaller) his willingness to sell (buy).

\section{B. Optimal Quotes}

\section{B.1. The Centralized Market}

Centralized markets were first studied in Ho and Stoll (1983). As they mention, one can view the process of setting bid-ask quotes in a centralized market as a progressive auction (an English auction) in which all dealers (except one) raise bid prices and lower ask prices to their reservation levels and thereby reveal their reservation prices. Notice that Bertrand competition among dealers makes the agent who can offer the most attractive price undercut all his competitors. In particular, the optimal ask price,

${ }^{6}$ Note that reservation fees may be negative if the inventory position makes certain transactions desirable. 
$A^{C}=1+a_{c}^{*}$, will be the second-lowest reservation selling price. Similarly, the optimal bid price, $B^{C}=1-b_{c}^{*}$, will be the second-highest reservation buying price. Lemma 1 implies that

$$
\begin{aligned}
& a_{c}^{*}=\frac{R \sigma^{2}}{2}\left(Q-2 I_{N-1}^{*}\right) \quad \text { and } \\
& b_{c}^{*}=\frac{R \sigma^{2}}{2}\left(Q+2 I_{2}^{*}\right) .
\end{aligned}
$$

Remark: In centralized markets, the optimal prices will be the secondbest reservation prices, no matter the dealers' attitude toward risk. Nevertheless, the optimal prices do depend on the risk attitudes as reservation prices depend upon them.

\section{B.2. The Fragmented Market}

In a fragmented market, dealer $i$ does not know the quotes of his competitors when he posts his quotes. One can hence view a fragmented market as a market functioning as a first price auction. A dealer will choose the quotes that maximize his expected utility assuming that his competitors follow ask and bid strategies that are strictly decreasing functions of their inventory positions. This expectation will be satisfied in equilibrium and it is, hence, rational.

To compute dealer $i$ 's expected utility, let us introduce the following notation: Let $\Pi_{a, i}$ denote the probability that dealer $i$ 's ask price is lower than his competitors' ask price. Since $a($.) is a strictly decreasing function,

$$
\Pi_{a, i}=P\left(a_{i}<a\left(Y_{N-1}\right)\right)=F^{N-1}\left(a^{-1}\left(a_{i}\right)\right) .
$$

Similarly, let $\Pi_{b, i}$ denote the probability that dealer $i$ 's bid price, $1-b_{i}$, is higher than his competitors' bid price, or, equivalently, $P\left(b_{i}<\operatorname{Min}_{j \neq i} b\left(I_{j}\right)\right)$. Since $b($.$) is assumed a strictly increasing function,$

$$
\Pi_{b, i}=P\left(b_{i}<b\left(Y_{1}\right)\right)=\left(1-F\left(b^{-1}\left(b_{i}\right)\right)\right)^{N-1} .
$$

By the symmetry of the analysis, we only develop the one corresponding to the ask price. Dealer $i$ chooses $a_{i}$ to maximize the expected utility of his terminal wealth, that is, if he sets the lowest ask price (an event that occurs with probability $\Pi_{a, i}$ ), then he trades with the public by selling $Q$ at his ask price. Otherwise, he does not trade. His expected utility will hence be

$$
\Pi_{a, i} E\left(U\left(W_{i}\left(a_{i}\right)\right) \mid I_{i}\right)+\left(1-\Pi_{a, i}\right) E\left(U\left(W_{i}(0)\right) \mid I_{i}\right),
$$


where $W_{i}(0)$ is dealer $i$ 's final wealth if he does not trade with the public, that is,

$$
W_{i}(0)=T_{i}-C+I_{i}(1+z)
$$

and $W_{i}\left(a_{i}\right)$ represents dealer $i$ 's final wealth if he sells the quantity $Q$ at the price $1+a_{i}$, that is,

$$
W_{i}(a)=T_{i}-C+I_{i}(1+z)+Q(a-z) .
$$

Using the definition of reservation quotes, ${ }^{7}$ we obtain

$$
E\left(U\left(W_{i}\left(a_{i}\right)\right) \mid I_{i}\right)=E\left(U\left(W_{i}(0)\right) \mid I_{i}\right) e^{-R Q\left(a_{i}-a_{r, i}\right)} .
$$

Since $E\left(U\left(W_{i}(0)\right) \mid I_{i}\right)$ is a negative constant with respect to $a_{i}$, dealer $i$ 's maximization problem can be rewritten as

$$
\operatorname{Max}_{a_{i}} \Pi_{a, i}\left[1-e^{-R Q\left(a_{i}-a_{r, i}\right)}\right] .
$$

Analogously, dealer $i$ chooses $b_{i}$ to maximize $\Pi_{b, i}\left[1-e^{-R Q\left(b_{i}-b_{r, i}\right)}\right]$.

The solutions to these problems characterize the optimal quotes in a fragmented market.

Proposition 1: Dealer i's optimal ask and bid prices are, respectively, $1+a_{i}$ and $1-b_{i}$, where

$$
\begin{aligned}
& a_{i}=a_{r, i}-\frac{1}{R Q} \ln \left(1-\frac{R^{2} \sigma^{2} Q \int_{-M}^{I_{i}} e^{-R Q\left[a_{r}(I)-a_{r}\left(I_{i}\right)\right]} F^{N-1}(I) d I}{F^{N-1}\left(I_{i}\right)}\right), \text { and } \\
& b_{i}=b_{r, i}-\frac{1}{R Q} \ln \left(1-\frac{R^{2} \sigma^{2} Q \int_{I_{i}}^{M} e^{-R Q\left[b_{r}(I)-b_{r}\left(I_{i}\right)\right]}(1-F(I))^{N-1} d I}{\left(1-F\left(I_{i}\right)\right)^{N-1}}\right)
\end{aligned}
$$

Dealer i's optimal quotes are strictly decreasing in his inventory position. Further, the surplus from trade, $a_{i}-a_{r, i}$ or $b_{i}-b_{r, i}$, is decreasing in $N$, and goes to zero as $N$ goes to infinity.

\footnotetext{
${ }^{7}$ Notice that both $E\left(U\left(W_{i}\left(a_{i}\right)\right) \mid I_{i}\right)$ and $E\left(U\left(W_{i}(0)\right) \mid I_{i}\right)$ are exponential functions because $W_{i}\left(a_{i}\right)$ and $W_{i}(0)$ are normally distributed once dealers know their inventory and the utility function is CARA.
} 
To better assess the role of the dealers' attitude toward risk in fragmented markets, let us now compare the optimal quotes under risk aversion, $A$ and $B$, with those obtained by Biais (1993), $A^{B}$ and $B^{B}$.

CorollaRY 1: The best ask (bid) quote satisfies $A\left(I_{N}^{*}\right)<A^{B}\left(I_{N}^{*}\right),\left(B\left(I_{1}^{*}\right)\right\rangle$ $\left.B^{B}\left(I_{1}^{*}\right)\right)$, where

$$
\begin{aligned}
A\left(I_{N}^{*}\right) & =1+R \sigma^{2}\left[\frac{Q}{2}-\frac{1}{R^{2} \sigma^{2} Q} \ln \left(E\left[e^{R^{2} \sigma^{2} Q Y_{N-1}} \mid Y_{N-1}<I_{N}^{*}\right]\right)\right] \\
A^{B}\left(I_{N}^{*}\right) & =1+R \sigma^{2}\left[\frac{Q}{2}-E\left[Y_{N-1} \mid Y_{N-1}<I_{N}^{*}\right]\right] \\
B\left(I_{1}^{*}\right) & =1-R \sigma^{2}\left[\frac{Q}{2}-\frac{1}{R^{2} \sigma^{2} Q} \ln \left(E\left[e^{-R^{2} \sigma^{2} Q Y_{1}} \mid Y_{1}>I_{1}^{*}\right]\right)\right], \quad \text { and } \\
B^{B}\left(I_{1}^{*}\right) & =1-R \sigma^{2}\left[\frac{Q}{2}+E\left[Y_{1} \mid Y_{1}>I_{1}^{*}\right]\right] .
\end{aligned}
$$

In Biais (1993), dealers have linear preferences over the surplus from trade. So, dealer $i$ sets his ask price to solve $\operatorname{Max}_{a_{i}} \Pi_{a, i}\left[R Q\left(a_{i}-a_{r, i}\right)\right]$. They hence behave as risk-neutral agents who mark up their selling prices in order to increase the expected surplus from trade. ${ }^{8}$ In contrast, for risk-averse agents marking up becomes less attractive as the marginal increment in utility associated with trading at a slightly higher ask price weighs less heavily than the possible loss from not trading due to such a high price. Thus, risk aversion makes dealers set prices closer to their reservation fees than under risk neutrality: It decreases the optimal ask quote and increases the optimal bid quote.

\section{Exogenous Public Trade}

As a benchmark, we first analyze the trading game under the proviso that the quantity traded by the public is fixed. More precisely, we now assume that if the liquidity shock occurs, then the public is equally likely to buy or sell the quantity $Q$. Notice that the public is now a passive agent, she does not take any decision. Our aim here is twofold: (a) on one hand, to perform a welfare comparison between the two market structures, ceteris paribus, and, (b) on the other hand, to study the entry stage in this simpler setting.

Dealers will prefer the market structure in which they can enjoy the largest expected utility. We now show that they set their optimal premia in a fragmented market equal to the certainty equivalent for the premia they would receive in a centralized market. To see this, consider the optimal ask

\footnotetext{
${ }^{8}$ Note that Biais' dealers have reservation fees equal to those of risk-averse dealers (i.e., $\left.a_{r, i}\right)$, whereas "pure" risk-neutral dealers have zero reservation fees.
} 
price. In a fragmented market, dealer $i$ 's maximization problem (see equation (A5) in the Appendix) implies that his selling premium satisfies

$$
e^{-R Q a_{i}}=\frac{\int_{-M}^{I_{i}} e^{-R Q a_{r}(I)} d F^{N-1}(I)}{F^{N-1}\left(I_{i}\right)}=E\left[e^{-R Q a_{r}\left(Y_{N-1}\right)} \mid Y_{N-1}<I_{i}\right] .
$$

By multiplying both sides by $-e^{R Q a_{r, i}}$, we have

$$
-e^{-R Q\left(a_{i}-a_{r, i}\right)}=E\left[-e^{-R Q\left[a_{r}\left(Y_{N-1}\right)-\alpha_{r}\left(I_{i}\right)\right]} \mid Y_{N-1}<I_{i}\right] .
$$

The left-hand side represents the utility of a dealer with inventory $I_{i}$ when he trades with the public at an ask price $1+a_{i}$ and gets a final wealth equal to the surplus from trade, that is, $Q\left(a_{i}-a_{r}\left(I_{i}\right)\right)$. The right-hand side represents the expected utility from trade of a dealer with inventory $I_{i}$ when he has the largest inventory (and, hence, the smallest reservation price) and receives a price equal to the smallest reservation price among his competitors. Hence, $a_{i}$ is the certainty equivalent for the premium a dealer with inventory $I_{i}$ would receive in a centralized market when winning. ${ }^{9}$

Proposition 2: Dealers are indifferent between the two market structures, ceteris paribus.

It is important to emphasize that dealers would also be indifferent between the two markets if they were risk neutral. Nevertheless, this indifference is due to the fact that risk-neutral dealers use price strategies that result in the same expected prices for the two markets. Under risk aversion, this is no longer the case, as dealers in fragmented markets bid more aggressively relative to the centralized market because they have utility reasons for wanting to unload excess inventory.

From the public's perspective, her order is an investment in a risky asset. Since her wealth will depend upon the best quotes posted in the two markets, a risk-averse public will care about the distributions of these prices. Next, Proposition 3 shows that prices set in fragmented markets are more attractive to the public than those posted in centralized markets.

Proposition 3: Prices in fragmented markets dominate prices in centralized markets in the sense of second-degree stochastic monotonic dominance (SDSMD). ${ }^{10}$

\footnotetext{
${ }^{9}$ Results in this subsection are consistent with results in the auction literature. In particular, Matthews (1987) has shown that a bidder with CARA utility bids in a first-price auction the certainty equivalent for the price he would pay in a second-price auction when winning. Waehrer, Harstad, and Rothkopf (1998) have shown that a second-price auction results in riskier prices than a first-price auction.

${ }^{10}$ For any two random variables, $x$ and $y, x$ displays $S D S M D$ over $y$ if all risk-averse and nonsatiable individuals prefer $x$ to $y$. Notice that SDSMD is weaker than second-degree stochastic dominance as the latter requires that all risk-averse individuals prefer $x$ to $y$ (see Chapter 2 in Huang and Litzenberger (1988)).
} 
The characterization of $S D S M D$ implies that fragmented markets lead to smaller (larger) expected selling (buying) prices than centralized markets; consequently, to smaller expected spreads. However, prices in fragmented markets are less risky than in centralized markets. Prior to trade, and conditional on the dealers' information, the ask price is fixed in fragmented markets but random in a centralized market (it depends on the ask prices set by the nonwinning dealers). These two facts make the public strictly prefer fragmented markets.

To summarize, fragmented markets are, ceteris paribus, more efficient (Pareto dominate) than centralized markets: Dealers are indifferent among the two market designs whereas the public strictly prefers fragmented markets.

Dealers' indifference across markets ensures that, ceteris paribus, the equilibrium number of dealers in the two markets will coincide. We now analyze the existence of such an equilibrium by studying the entry stage.

At Stage 1, if agent $i$ does not enter the market, he forgoes the possibility of trading, but he saves the entry cost. His expected utility will be $E\left[U\left(W_{i}(0)\right) e^{-R C}\right]$. If he enters the market and receives inventory $I_{i}$, he can face three possible spots (see Figure 1):

1. His inventory is larger than the largest inventory among his competitors. In this case, he will sell at ask if the public buys and he will not trade in any other case.

2. His inventory is smaller than the smallest inventory among his competitors. Then, he will buy at bid if the public sells and he will not trade in any other case.

3 . His inventory lies between the smallest and the largest inventory positions among his competitors. In this case, he will not trade.

Consequently, his ex ante (before inventory positions are drawn) expected utility will be $\int_{-M}^{M} E\left[U\left(W_{i}\right) \mid I_{i}\right] f\left(I_{i}\right) d I_{i}$, where

$$
\begin{aligned}
E\left[U\left(W_{i}\right) \mid I_{i}\right]= & \frac{\lambda}{2}\left[F^{N-1}\left(I_{i}\right) E\left[U\left(W_{i}\left(a_{i}\right)\right) \mid I_{i}\right]\right. \\
& \left.+\left(1-F\left(I_{i}\right)\right)^{N-1} E\left[U\left(W_{i}\left(b_{i}\right)\right) \mid I_{i}\right]\right] \\
& +\left[1-\frac{\lambda}{2}\left(F^{N-1}\left(I_{i}\right)+\left(1-F\left(I_{i}\right)\right)^{N-1}\right)\right] E\left[U\left(W_{i}(0)\right) \mid I_{i}\right] .
\end{aligned}
$$

The equilibrium number of dealers will be the greatest positive integer, $N$, such that the expected utility of those agents who choose to become dealers is at least as large as the expected utility of those agents who do not enter the market, or, equivalently, the greatest positive integer for which $\phi(N)$ is nonnegative, where

$$
\phi(N)=\int_{-M}^{M} E\left[U\left(W_{i}\right) \mid I_{i}\right] f\left(I_{i}\right) d I_{i}-e^{-R C} \int_{-M}^{M} E\left[U\left(W_{i}(0)\right) \mid I_{i}\right] f\left(I_{i}\right) d I_{i} .
$$


PROPOSITION 4: There exists an equilibrium number of dealers larger than one iff $\phi(2) \geq 0$. If an equilibrium exists, it will be unique. Further, the equilibrium number of dealers is strictly increasing in both the size of the market order $(Q)$ and the frequency of trades $(\lambda)$, and it is strictly decreasing in the cost of entry $(C)$.

The logic of the condition for existence is as follows. We first note that $\phi(N)$ is a strictly decreasing function: More dealers means fiercer competition and hence lower expected utility. If there were an infinite number of dealers, then they would set quotes equal to their reservation quotes resulting in zero profits when trading (see Proposition 1). Thus, $\phi(N)$ goes to a negative number as $N$ goes to infinity since becoming a dealer is unprofitable (they have to pay the cost of entry and they do not gain any profits). Therefore, $\phi(2) \geq 0$ is a necessary and sufficient condition to guarantee the existence of a "nonmonopolist" equilibrium number of dealers.

The comparative statics in Proposition 4 are quite intuitive. If the cost of entry increases, then entry becomes less attractive and, hence, the equilibrium number of dealers will decrease. In contrast, if the probability of trading increases (as reflected by an increase in $\lambda$ ), entry becomes more attractive, since it is more likely to enjoy the surplus from trade. Similar arguments apply to changes in the size of the market order.

\section{The Market Order}

We will now determine the size of the public order in the two market structures by taking into account the solution to the trading stage derived in Section II. As for the benchmark case, we provide a welfare comparison between the two markets based on the solution to the public's problem.

Doing a similar reasoning as in Lemma 1 , the public has reservation buying (selling) prices, $p_{r}(-L)\left(p_{r}(L)\right)$, given by

$$
\begin{aligned}
p_{r}(-L) & =1-\frac{R \sigma^{2}}{2}(Q-2 L), \quad \text { and } \\
p_{r}(L) & =1+\frac{R \sigma^{2}}{2}(Q+2 L) .
\end{aligned}
$$

Straightforward computations allow us to write the public's maximization problem when she is in a short position as follows:

$$
\operatorname{Max}_{Q} E\left[-e^{-R Q\left(p_{r}(-L)-A^{S}\right)}\right],
$$

where $A^{S}$ denotes the best ask quote in market structure $S, S=C, F$. Similarly, when the public is in a long position, her maximization problem becomes: 


$$
\operatorname{Max}_{Q} E\left[-e^{-R Q\left(B^{S}-p_{r}(L)\right)}\right],
$$

where $B^{S}$ denotes now the best bid quote in market structure $S$.

Since the problem is symmetric, we will only determine the size of the public's purchase. Let us first note that Biais (1993) uses a Taylor expansion to get a linear approximation in equation (18). Thus, Biais' risk-neutral public only cares about the expected surplus from trade. Further, in his setting, the per-unit expected surplus, $E\left[p_{r}(-L)-A^{S}\right]$, is equal in the two markets (recall that expected prices were equal). Consequently, the optimal market order will be the same in the two markets. More precisely,

$$
Q^{B}=\frac{1}{2}\left(L+E\left(I_{N-1}^{*}\right)\right)
$$

We will now show that under risk aversion, the public behaves differently in the two markets.

\section{A. Fragmented Market}

The public, correctly, infers that $A^{F}=A\left(I_{N}^{*}\right)$, and she chooses the size of her market order to maximize

$$
\underset{Q}{\operatorname{Max}_{Q}}-E\left[E^{-1}\left[e^{-R^{2} \sigma^{2} Q\left(Q-L-I_{N-1}^{*}\right)} \mid I_{N}^{*}\right]\right]
$$

\section{B. Centralized Market}

The public now, correctly, infers that $A^{C}=1+a_{c}^{*}\left(I_{N-1}^{*}\right)$. Consequently, her maximization problem becomes

$$
\underset{Q}{\operatorname{Max}} E\left[-e^{R^{2} \sigma^{2} Q\left(Q-L-I_{N-1}^{*}\right)}\right] .
$$

Denoting by $Q^{F}\left(Q^{C}\right)$ the public's optimal market order when she trades in a fragmented (centralized) market, the comparison between them gives rise to the following result.

Proposition 5: The optimal market order is larger in the fragmented market than in the centralized market.

The proof of Proposition 5 gives, as a by-product, the following auxiliary result:

$$
Q^{F}>Q^{B}>Q^{C}
$$

This tells us how the size of the market order changes as we move parametrically from markets in which all traders (dealers and investors) are risk neutral to markets in which they are all risk averse. Under fragmentation, 
risk aversion brings about two opposite effects: (a) a risk effect and (b) a price effect. The risk effect describes the idea that because the market order is an investment in a risky asset, a risk-averse individual (our public) will invest less than a risk-neutral individual (Biais' public). The price effect measures the favorable outcome for the investing public of the fiercer competition brought on by the dealers' risk aversion. ${ }^{11}$ The first inequality in (23) tells us that when markets are fragmented, the price effect dominates the risk effect, so that risk aversion increases the size of the market order. When markets are centralized, however, the price effect is absent and there is only a risk effect. Consequently, as the second inequality demonstrates, Biais' risk-neutral public invests more than our risk-averse public when they face the same prices.

Proposition 5 shows that market liquidity, measured by spreads and volume, is greater in the less pretrade transparent market: Expected spreads are smaller and volume is higher. This result is consistent with the empirical evidence reported in Madhavan, Porter, and Weaver (1999). These authors conclude that transparency may have detrimental effects on liquidity. ${ }^{12}$ We now show that it has detrimental effects on welfare as well.

PRoposition 6: All market participants strictly prefer to trade in fragmented markets, ceteris paribus. ${ }^{13}$

The arguments behind Proposition 6 are intuitive. Dealers prefer the market with the largest volume of trade, as they are indifferent between the two markets for fixed $Q$ (Proposition 2) and their expected utility is increasing in the size of the market order (Proposition 4). The public was already better off in fragmented markets for fixed $Q$ (Proposition 3), hence, the optimality of $Q^{F}$ only reinforces this preference.

Proposition 7: The equilibrium number of dealers will be larger when markets are fragmented.

In Proposition 4, we showed that the equilibrium number of dealers is strictly increasing in $Q$. This result and Proposition 5 show our claim. Note that the public's preference for fragmentation is strengthened as, in equilibrium, there will be more dealers trading in the fragmented markets.

\section{Discussion}

The model was based on a number of simplifying assumptions, and at this point, we are interested in assessing the impact of relaxing them in our conclusions. In this section, some alternative formulations are examined.

\footnotetext{
${ }^{11}$ Formally, the prices set by risk-averse dealers first-order stochastically dominate the prices set by risk-neutral dealers (see Corollary 1).

12 They address pretrade transparency in the form of public display of limit order books using data from the Toronto Stock Exchange, before and after the limit order book was publicly disseminated on April 1990.

${ }^{13}$ This could be the case in countries where the number of liquidity suppliers is fixed by the regulation authority.
} 


\section{A. Private Information}

One extension of the model is to consider that the market order can come from one of two possible types of investors, either from a liquidity trader or from a perfectly informed trader. This extension can be analyzed using a simple model similar to the one proposed by Madhavan (1995) in which the risky asset can take on only two possible values, low and high. ${ }^{14}$ Let us first concentrate on the case in which the market order is determined exogenously. The liquidity trader buys or sells a fixed quantity, $Q$ units of the asset, for exogenous liquidity reasons. The informed trader also buys or sells $Q$ units of the asset. She wants to buy if she receives good news, and wants to sell otherwise. Thus, the direction of the market order now conveys some information about the final value of the asset. Consequently, dealers will take it into account for revising their beliefs.

In this new model, the adverse selection induced by asymmetric information causes the expected spreads to widen as dealers will protect themselves from information-based trading by setting worse prices. However, this effect is common to both markets and it does not hence reverse the ranking between them. Note that dealers update their beliefs identically in the two markets: They start with the same prior beliefs about the true value of the asset and they receive the same order size.

Consider now that the public chooses her order optimally. If the informed trader's optimal order size were different from the one selected by the liquidity trader, then our previous results may not hold. However, this will not occur in equilibrium. Notice that an informed trader who acts as a liquidity trader can profit from her informational advantage, whereas if she does not camouflage, she cannot capitalize on her advantage. If order sizes were different, dealers would infer which market order comes from an informed investor, and they would use this information to protect themselves by setting prices closer to the true value of the risky asset. This would reduce the informed investor's profits.

\section{B. Distribution of Inventories}

Throughout this paper, we assume that when dealers form their expectations of the distributions of underlying inventories, they use the same distribution, $F(I)$, in the two markets. Clearly, this is not a realistic assumption if one uses a dynamic model where dealers' beliefs depend on the history of past trades, on the information flow, and on their own inventory position. Dealers will hence form conjectures regarding $F(I)$ that are neither common among them, nor equal in the two markets.

\footnotetext{
${ }^{14}$ We will only mention here some results without stating either the specifics of the underlying model or the formal proofs. For a complete analysis of this extension, the reader is referred to our working paper (Frutos and Manzano (2000)).
} 
To further illustrate the asymmetry in beliefs that a dynamic model generates, consider a two-period model in which dealers compete to get a purchase market order in $t=1$, and an unknown type of market order (purchase or sale) in $t=2$. Assume, for the sake of simplicity, that at $t=1$ inventories are drawn from the same distribution, $F(I)$, in the two markets. Consider first the beliefs at $t=2$ of the dealers who did not trade in the first period. In a centralized market they will, at $t=2$, know all the inventories except that of the dealer who did trade (their common belief will be that it lies in the interval $\left[I_{N-1}^{*}-Q, M-Q\right]$ ). By contrast, a dealer with inventory $I_{i}$ who did not trade in a fragmented market will only know that there is a dealer whose inventory lies in the interval $\left[I_{i}-Q, M-Q\right]$. Notice that these dealers' beliefs are not common, as they depend on the inventory position. Consider now the beliefs of the trading dealer. In the centralized market, he will know all the inventories, whereas in the fragmented market, he will only know that his competitors' inventories are smaller than his..$^{15}$

To the extent that there is more information flow in the centralized market, it could be argued that $F(I)$ has to be tighter in this market. We now explore how this fact could alter our results. We first note that if $F$ were a degenerative distribution (equal inventories for all), then the two market designs would be fully equivalent, since there would be complete information about inventories and, consequently, no risk. One should then expect smaller expected prices in the centralized market (as compared to the fragmented market) for a sufficiently tight $F(I)$. We now show in an example that this is indeed the case.

Let $F(I)$ be a uniform distribution function with $I \in[-M, M]$. Assume, for the sake of simplicity, that two dealers compete to get a market purchase of size one. Finally, let $R=\sigma^{2}=1$. Straightforward computations yield

$$
\begin{aligned}
& E\left[A_{C}^{*}(M)\right]=\frac{3}{2}+\frac{1}{3} M, \text { and } \\
& E\left[A_{F}^{*}(M)\right]=1.5-E\left[\ln \left(-\frac{-e^{I_{2}^{*}}+e^{-M}}{I_{2}^{*}+M}\right)\right] .
\end{aligned}
$$

Figure 2 plots these functions. Notice that $E\left[A_{C}^{*}(1)\right]=1.83<1.85=$ $E\left[A_{F}^{*}(2)\right]$. Thus, a tighter distribution of inventories in a centralized market as compared to a fragmented market $(I \in[-1,1]$ versus $I \in[-2,2])$ does result in smaller expected prices in the former market design.

\footnotetext{
${ }^{15}$ We do not know how our results might be altered in this richer model. Note that it is complex to study dynamic fragmented markets, as dealers' beliefs will not be symmetric. To get a hint on the difficulties, the reader is referred to Maskin and Riley (2000).
} 


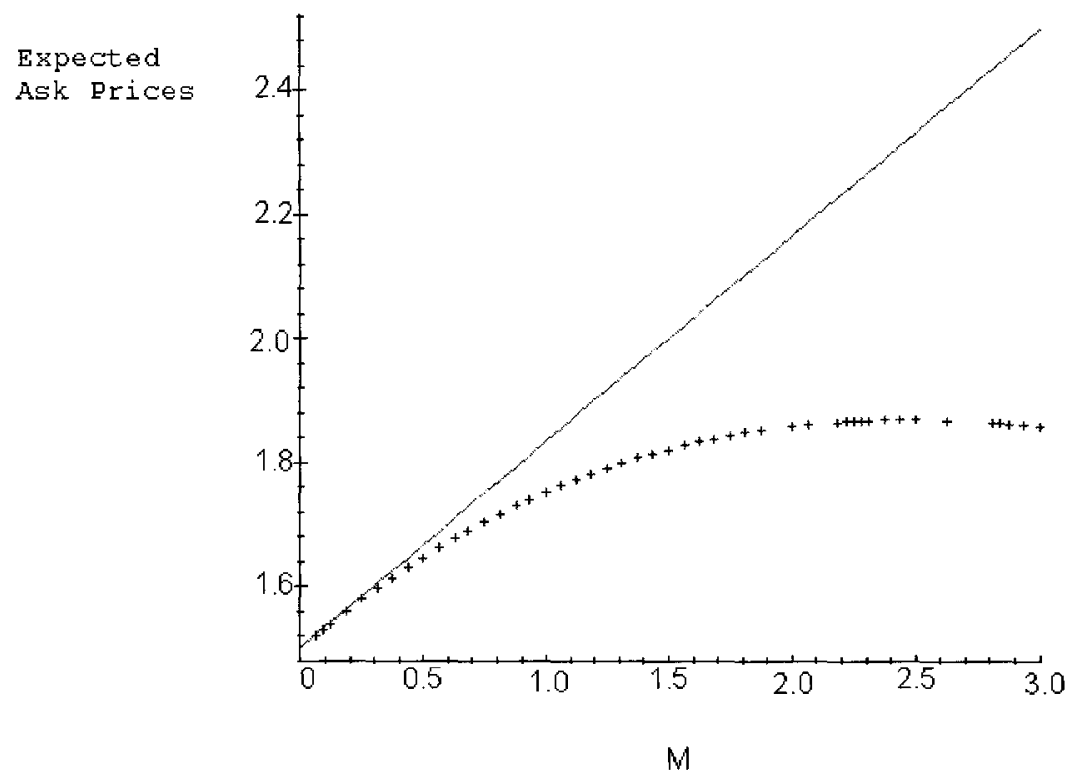

Figure 2. Expected ask prices for different ranges of inventories. The straight line pertains to the centralized market.

\section{Pretrade and Posttrade Transparency}

The Securities and Investment Board has suggested that the dissemination of quotes may, in a sense, substitute for posttrade information "by providing traders with sufficient information to make informed trading decisions" (Securities and Investment Board (1994), p. 8). Even though this role of quote transparency remains conjectural, it is interesting to note that our results for pretrade transparency are aligned with those obtained in the context of posttrade transparency. In particular, the result that expected spreads under fragmentation are narrower than under centralization is also derived in Madhavan (1995) and in Naik, Neuberger, and Viswanathan (1999). Since the former considers a setup closer to ours, let us now discuss this work in more detail.

In Madhavan (1995), delayed reporting allows dealers to gauge the information conveyed by a trade and exploit it later with other traders. This encourages dealers to offer better prices in less posttrade transparent markets. In other words, dealers profit from fragmentation because it results in less price competition: Nondisclosure allows them to participate in future trading to profit from the current acquired information. In contrast, in our framework, dealers offer better prices in fragmented markets because of risk aversion. Fragmentation results, in our setup, in more price competition. If we were to consider a dynamic model with two periods of trade (as in Madhavan), one could expect that spreads in the first period would be, under fragmentation, narrower in the dynamic model than in the static one. 
The intuition is that, at period one, dealers have two reasons to offer better prices: (a) risk aversion and (b) the possibility of exploiting the acquired information in subsequent trading.

\section{Conclusions and Policy Implications}

Securities markets worldwide have various degrees of public quote disclosure with implications that are not well understood. We consider here the impact of quote visibility by analyzing fragmented and centralized markets: Two market structures which differ in the degree of quote dissemination. An interesting conclusion can be drawn from our analysis: The move toward greater transparency may have detrimental effects. The important upshot is that risk-averse dealers use less aggressive price strategies in the more transparent market because quote dissemination alleviates uncertainty about the prices quoted by other dealers and, hence, reduces competition.

There are, certainly, other countervailing forces that may offset the advantages of fragmented markets. In particular, we show in this paper that a sufficiently tight distribution of underlying inventories in a centralized market, as compared to the distribution in a fragmented market, can result in smaller expected ask prices in the former than in the latter. Further, this seems a more realistic assumption than the one considered in this paper (equal distribution of underlying inventories) if one considers that there is repeated interaction between dealers. Another countervailing force could be endogenous informed traders' entry decisions. We have shown that an investor has more incentives to collect information (to own a private signal about the asset value) under fragmentation. The endogenous distribution of traders could then be different in the two markets with, more likely, a larger proportion of informed traders in fragmented markets. Adverse selection concerns could then widen the expected spread in the fragmented market. Which of the two effects (risk aversion or adverse selection) will dominate is unclear to us.

Our results here may be contrasted with those of Flood et al. (1999) who also investigate quote transparency issues in an experimental study. They find that quote transparency reduces opening spreads and increases trading volume due to lower search costs. While their results conflict with ours, the differences in the setting can account for this. They consider quote-driven markets in which investors trade against outstanding prices set by riskneutral dealers. Further, interdealer trading is the bulk of the trading activity. In contrast, we consider order-driven markets where investors submit orders first, and then dealers set prices. ${ }^{16}$

Our research has a number of implications for regulatory policy. We find that increased pretrade transparency reduces dealers' need to compete for the order flow and, consequently, results in worse prices. This result suggests that if price strategies depend on private information, then opaque-

${ }^{16}$ Order-driven trading platforms include Instinet and AZX in Nasdaq. 
ness of markets may be preferred as liquidity may be enhanced when markets are less transparent. If we combine our results with those showing that posttrade transparent markets are more informationally efficient, one could argue that the crucial issue in market design is the degree of transparency rather than its absolute attainment. It seems plausible to us that the combination of less pretrade transparent microstructures with more posttrade transparent ones could improve the advantages of each separately.

\section{Appendix}

Proof of Lemma 1: See Ho and Stoll (1983) and/or Biais (1993).

Proof of Proposition 1: Dealer $i$ chooses $a_{i}$ to maximize $\Pi_{a, i}\left(1-e^{-R Q\left(a_{i}-\alpha_{r, i}\right)}\right)$. His optimal ask fee is the solution to the following differential equation:

$$
\frac{d \Pi_{a, i}}{d a_{i}}\left[1-e^{-R Q\left(a_{i}-a_{r, i}\right)}\right]+\Pi_{a, i}\left[-e^{-R Q\left(a_{i}-a_{r, i}\right)}(-R Q)\right]=0,
$$

where

$$
\frac{d \Pi_{a, i}}{d a_{i}}=(N-1) F^{N-2}\left(a^{-1}\left(a_{i}\right)\right) f\left(a^{-1}\left(a_{i}\right)\right) \frac{d a^{-1}\left(a_{i}\right)}{d a_{i}} .
$$

At a symmetric equilibrium, the differential equation becomes

$$
\frac{d F^{N-1}\left(I_{i}\right)}{d I_{i}} \frac{d I_{i}}{d a_{i}}\left[1-e^{-R Q\left(a_{i}-a_{r, i}\right)}\right]+F^{N-1}\left(I_{i}\right)\left[-e^{-R Q\left(a_{i}-a_{r, i}\right)}(-R Q)\right]=0 .
$$

Multiplying by $\left(d a_{i} / d I_{i}\right) e^{-R a_{r, i} Q}$, it follows that

$$
\frac{d F^{N-1}\left(I_{i}\right)}{d I_{i}}\left(e^{-R Q a_{r, i}}-e^{-R Q a_{i}}\right)+F^{N-1}\left(I_{i}\right)\left(-e^{-R Q a_{i}}(-R Q) \frac{d a_{i}}{d I_{i}}\right)=0 .
$$

Integrating and operating, we derive the optimal ask fee. In particular,

$$
a_{i}=\frac{-1}{R Q} \ln \left(F^{-(N-1)}\left(I_{i}\right) \int_{-M}^{I_{i}} e^{-R Q a_{r}(I)} d F^{N-1}(I)\right) .
$$

Straightforward computations give the desired expression for $a_{i}$. 
We now analyze the derivative of $a(\cdot)$ with respect to $I_{i}$. Using (A4) we obtain

$$
\frac{d a_{i}}{d I_{i}}=-\frac{\frac{d F^{N-1}\left(I_{i}\right)}{d I_{i}}}{R Q e^{-R Q a_{i} F^{N-1}\left(I_{i}\right)}}\left(e^{-R Q a_{r, i}}-e^{-R Q a_{i}}\right)
$$

Since the right-hand side of the previous equality is negative (recall that $a_{i}>a_{r, i}$ ), it is deduced that the ask fee is strictly decreasing in the inventory position. Let us now examine the derivative of $a_{i}$ with respect to $N$. This derivative,

$$
\frac{d a_{i}}{d N}=\frac{R \sigma^{2} \int_{-M}^{I_{i}} e^{-R Q\left[a_{r}(I)-a_{r}\left(I_{i}\right)\right]}\left(\frac{F(I)}{F\left(I_{i}\right)}\right)^{N-1} \ln \left(\frac{F(I)}{F\left(I_{i}\right)}\right) d I}{\left(1-\frac{R^{2} \sigma^{2} Q \int_{-M}^{I_{i}} e^{-R Q\left[a_{r}(I)-a_{r}\left(I_{i}\right)\right]} F^{N-1}(I) d I}{F^{N-1}\left(I_{i}\right)}\right)},
$$

is negative as $I<I_{i}$. Finally, $a_{i} \rightarrow a_{r, i}$ as $N \rightarrow \infty$, since for all $I<I_{i}$, it is satisfied that $\left(F(I) / F\left(I_{i}\right)\right)^{N-1} \rightarrow 0$ as $N \rightarrow \infty$. Q.E.D.

Proof of Corollary 1: The expression for $A\left(I_{N}^{*}\right)$ is derived from (A5) and Lemma 1. Using $A\left(I_{N}^{*}\right)$ and $A^{B}\left(I_{N}^{*}\right)$, it is clear that $A\left(I_{N}^{*}\right)<A^{B}\left(I_{N}^{*}\right)$ if

$$
E\left[e^{R^{2} \sigma^{2} Q Y_{N-1}} \mid Y_{N-1}<I_{N}^{*}\right]>e^{R^{2} \sigma^{2} Q E\left[Y_{N-1} \mid Y_{N-1}<I_{N}^{*}\right]} .
$$

Similarly, $B\left(I_{1}^{*}\right)>B^{B}\left(I_{1}^{*}\right)$ if

$$
E\left[e^{-R^{2} \sigma^{2} Q Y_{1}} \mid Y_{1}>I_{1}^{*}\right]>e^{-R^{2} \sigma^{2} Q E\left[Y_{1} \mid Y_{1}>I_{1}^{*}\right]} .
$$

Both conditions are ensured by Jensen's inequality due to the convexity of the exponential function. Q.E.D.

Proof of Proposition 3: It is well known that second-degree stochastic monotonic dominance can be characterized in the following way:

$$
x \gtrsim y \Leftrightarrow y=x+\varepsilon, \quad \text { with } E(\varepsilon \mid x) \leq 0 .
$$

We now show that $-A^{F} \gtrsim-A^{C}$ and $B^{F} \gtrsim B^{C}$ hold. ${ }^{17}$

17 The negative sign in the best ask prices is due to the fact that they are buying prices from the public's perspective. 
Consider first the best ask price. Since $-A^{C}=-A^{F}-A^{C}+A^{F}$, our claim will hold if $E\left[-A^{C}+A^{F} \mid A^{F}\right] \leq 0$. The properties of the conditional expectation imply

$$
E\left[-A^{C}+A^{F} \mid A^{F}\right]=-E\left[a^{C} \mid A^{F}\right]+a^{F} .
$$

Since the public is a strictly risk-averse investor and $a^{F}$ is the certainty equivalent of $a^{C}$, it must be the case that $a^{F}<E\left[a^{C} \mid A^{F}\right]$. Consequently,

$$
E\left[-A^{C}+A^{F} \mid A^{F}\right]<-E\left[A^{C} \mid A^{F}\right]+E\left[A^{C} \mid A^{F}\right]=0 .
$$

Similar arguments apply for the bid price. Just notice that $B^{C}=B^{F}+B^{C}-B^{F}$ and that $E\left[B^{C}-B^{F} \mid B^{F}\right]=E\left[1-b^{C} \mid B^{F}\right]-1+b^{F}=b^{F}-E\left[b^{C} \mid B^{F}\right]<0$, where the last inequality follows from the fact that $b^{F}$ is the certainty equivalent of $b^{C}$. Q.E.D.

Proof of Proposition 4: The equilibrium number of dealers is the greatest positive integer such that $\phi(N)$ is nonnegative. Straightforward computations using the expressions for the optimal quotes yield

$$
\begin{aligned}
\phi(N)=E[ & E\left[U\left(W_{i}(0)\right) \mid I_{i}\right] \\
& \left.\times\left(1-e^{-R C}-\frac{\lambda\left(F^{N-1}\left(I_{i}\right)+\left(1-F\left(I_{i}\right)\right)^{N-1}\right)}{2}+\frac{\lambda \gamma\left(I_{i}\right)}{2}\right)\right],
\end{aligned}
$$

where

$$
\gamma\left(I_{i}\right)=\int_{-M}^{I_{i}} e^{-R^{2} \sigma^{2} Q\left(I_{i}-x\right)} d F^{N-1}(x)-\int_{I_{i}}^{M} e^{-R^{2} \sigma^{2} Q\left(x-I_{i}\right)} d(1-F(x))^{N-1} .
$$

Integrating by parts the expressions in $\gamma\left(I_{i}\right)$, the function $\phi(N)$ can be rewritten as follows:

$$
\begin{aligned}
\phi(N)= & \left(1-e^{-R C}\right) E\left[E\left[U\left(W_{i}(0)\right) \mid I_{i}\right]\right] \\
& -\left(\lambda R^{2} \sigma^{2} Q / 2\right) E\left[E\left[U\left(W_{i}(0)\right) \mid I_{i}\right] \theta\left(I_{i}\right)\right],
\end{aligned}
$$

where the expression for $\theta\left(I_{i}\right)$ is given by

$$
\theta\left(I_{i}\right)=\int_{-M}^{I_{i}} e^{-R^{2} \sigma^{2} Q\left(I_{i}-x\right)} F^{N-1}(x) d x+\int_{I_{i}}^{M} e^{-R^{2} \sigma^{2} Q\left(x-I_{i}\right)}(1-F(x))^{N-1} d x .
$$

Notice that $\phi(N)$ is continuous in $N$. Moreover, if we differentiate it, we obtain that

$$
\frac{\partial \phi(N)}{\partial N}=-\lambda R^{2} \sigma^{2} Q / 2 E\left[E\left[U\left(W_{i}(0)\right) \mid I_{i}\right] \frac{\partial \theta\left(I_{i}\right)}{\partial N}\right] .
$$


Both $E\left[U\left(W_{i}(0)\right) \mid I_{i}\right]$ and $\partial \theta\left(I_{i}\right) / \partial N$ are always negative. Hence, it follows that $\phi(N)$ is strictly decreasing in $N$. Further, $\phi(N)$ goes to $\left[1-e^{-R C}\right] \times$ $E\left[U\left(W_{i}(0)\right)\right]$, a negative number, as $N$ goes to infinity. Thus $\phi(2) \geq 0$ guarantees the existence of an equilibrium number of dealers larger than one.

Finally, since $\phi(N)$ is strictly increasing in $Q$, it is deduced that the equilibrium number of dealers increases as $Q$ does. A similar argument applies to changes in $\lambda$. In contrast, as $C$ increases, $\phi(N)$ decreases and, hence, the equilibrium number of dealers decreases. Q.E.D.

The proof of Proposition 5 relies on the following auxiliary result due to Kimball (1951).

Kimball's inequality. Let $U$ be a univariate random variable. If $g_{1}, \ldots, g_{p}$ are bounded, nonnegative and (strictly) monotone in the same direction, then

$$
E\left[\Pi_{i=1}^{p} g_{i}(U)\right](>) \geq \Pi_{i=1}^{p} E\left[g_{i}(U)\right] .
$$

CorollarY: If $g_{1}, g_{2}$ are bounded, nonnegative, and such that $g_{1}$ is (strictly) monotone increasing and $\mathrm{g}_{2}$ is (strictly) monotone decreasing, then

$$
E\left[g_{1}(U) g_{2}(U)\right](<) \leq E\left[g_{1}(U)\right] E\left[g_{2}(U)\right] .
$$

Proof of Corollary: Let $f(U)=C-g_{2}(U)$, where $C$ is a constant large enough such that $f$ is nonnegative. This function is bounded and monotone increasing. Applying Kimball's inequality to the functions $g_{1}$ and $f$, we obtain that

$$
E\left[g_{1}(U) f(U)\right] \geq E\left[g_{1}(U)\right] E[f(U)] .
$$

Substituting $f$ in the last inequality and simplifying, the desired inequality is derived. Q.E.D.

Proof of Proposition 5: From the f.o.c. in the centralized market, it follows that

$$
E\left[e^{-R^{2} \sigma^{2} Q^{C} I_{N-1}^{*}}\left(2 Q^{C}-L+M-M-I_{N-1}^{*}\right)\right]=0
$$

or, equivalently,

$$
\left.\left(2 Q^{C}-L-M\right) E\left[e^{-R^{2} \sigma^{2} Q^{C} I_{N-1}^{*}}\right]+E\left[e^{-R^{2} \sigma^{2} Q^{C} I_{N-1}^{*}\left(M-I_{N-1}^{*}\right.}\right)\right]=0 .
$$

Using Kimball's inequality, we have that

$$
E\left[e^{-R^{2} \sigma^{2} Q^{C} I_{N-1}^{*}}\left(M-I_{N-1}^{*}\right)\right]>E\left[e^{-R^{2} \sigma^{2} Q^{C} I_{N-1}^{*}}\right] E\left[M-I_{N-1}^{*}\right] .
$$


Thus,

$$
0>E\left[e^{-R^{2} \sigma^{2} Q^{C} I_{N-1}^{*}}\right] E\left[2 Q^{C}-L-I_{N-1}^{*}\right]
$$

The above inequality implies

$$
Q^{C}<\frac{1}{2}\left(L+E\left(I_{N-1}^{*}\right)\right)
$$

Similarly, from the f.o.c. in the fragmented market, it follows that

$$
E\left[E\left[e^{R^{2} \sigma^{2} Q^{F} I_{N-1}^{*}}\left(2 Q^{F}-L+M-M-I_{N-1}^{*}\right) \mid I_{N}^{*}\right] E^{-2}\left[e^{R^{2} \sigma^{2} Q^{F} I_{N-1}^{*}} \mid I_{N}^{*}\right]\right]=0
$$

or, equivalently,

$$
E\left[\frac{2 Q^{F}-L-M}{E\left[e^{R^{2} \sigma^{2} Q^{F} I_{N-1}^{*}} \mid I_{N}^{*}\right]}\right]+E\left[\frac{E\left[e^{R^{2} \sigma^{2} Q^{F} I_{N-1}^{*}}\left(M-I_{N-1}^{*}\right) \mid I_{N}^{*}\right]}{E^{2}\left[e^{R^{2} \sigma^{2} Q^{F} I_{N-1}^{*}} \mid I_{N}^{*}\right]}\right]=0
$$

Let us denote by $H$ to the second term in the left-hand side of (A27). Straightforward computations allow us to rewrite $H$ as follows:

$$
H=\int_{-M}^{M} \frac{F^{-(N-1)}(I) \int_{-M}^{I} e^{R^{2} \sigma^{2} Q^{F} Z}(M-Z) d F^{N-1}(Z)}{F^{-2(N-1)}(I)\left(\int_{-M}^{I} e^{R^{2} \sigma^{2} Q^{F} Z} d F^{N-1}(Z)\right)^{2}} d F^{N}(I) .
$$

The corollary to Kimball's inequality implies

$$
\int_{-M}^{I} e^{R^{2} \sigma^{2} Q^{F} Z}(M-Z) d H(Z)<\int_{-M}^{I} e^{R^{2} \sigma^{2} Q^{F} Z} d H(Z) \int_{-M}^{I}(M-Z) d H(Z) .
$$

Therefore,

$$
H<\int_{-M}^{M} \frac{\int_{-M}^{I}(M-Z) d F^{N-1}(Z)}{F^{-(N-1)}(I) \int_{-M}^{I} e^{R^{2} \sigma^{2} Q^{F} Z} d F^{N-1}(Z)} d F^{N}(I) .
$$


Let us now define three auxiliary functions. Let

$$
\begin{aligned}
& g_{1}(I)=\int_{-M}^{I}(M-Z) d F^{N-1}(Z), \\
& g_{2}(I)=\left(F^{-(N-1)}(I) \int_{-M}^{I} e^{R^{2} \sigma^{2} Q^{F} Z} d F^{N-1}(Z)\right)^{-1}, \text { and } \\
& g_{3}(I)=\frac{\int_{-M}^{I}(M-Z) d F^{N-1}(Z)}{\int_{-M}^{I} e^{R^{2} \sigma^{2} Q^{F} Z} d F^{N-1}(Z)} .
\end{aligned}
$$

By using these auxiliary functions, we can rewrite (A30) as follows:

$$
H<\int_{-M}^{-M+\epsilon} g_{3}(I) F^{(N-1)}(I) d F^{N}(I)+\int_{-M+\epsilon}^{M} g_{1}(I) g_{2}(I) d F^{N}(I) .
$$

The function $g_{3}(I)$ is bounded in the interval $[-M,-M+\epsilon]$ (note that $\lim _{I \rightarrow-M} g_{3}(I)$ is equal to $\left.2 M e^{R^{2} \sigma^{2} Q^{F} M}\right)$. Hence, if $K$ denotes an upper bound of $g_{3}(I)$, it is easy to see that

$$
\int_{-M}^{-M+\epsilon} g_{3}(I) F^{(N-1)}(I) d F^{N}(I)<K\left[F^{N}(-M+\epsilon)-F^{N}(-M)\right]
$$

The functions $g_{1}(I)$ and $g_{2}(I)$ are bounded and nonnegative in the interval $[-M+\epsilon, M]$. In addition, $g_{1}$ is monotone increasing and $g_{2}$ is monotone decreasing. Consequently, appealing to the corollary to Kimball's inequality, we know that

$$
\int_{-M+\epsilon}^{M} g_{1}(I) g_{2}(I) d F^{N}(I)<\int_{-M+\epsilon}^{M} g_{2}(I) d F^{N}(I) \int_{-M+\epsilon}^{M} g_{1}(I) d F^{N}(I) .
$$

Hence, the combination of the two previous results gives

$$
H<K\left[F^{N}(-M+\epsilon)-F^{N}(-M)\right]+\int_{-M+\epsilon}^{M} g_{2}(I) d F^{N}(I) \int_{-M+\epsilon}^{M} g_{1}(I) d F^{N}(I)
$$


As $\epsilon$ goes to zero, the continuity of $F$ and the definition of $g_{1}$ and of $g_{2}$ yield

$$
H \leq E\left[E^{-1}\left[e^{R^{2} \sigma^{2} Q^{F} I_{N-1}^{*}} \mid I_{N}^{*}\right]\right] \int_{-M}^{M}\left(\int_{-M}^{I}(M-Z) d F^{N-1}(Z)\right) d F^{N}(I) .
$$

Further, as $F(\cdot)$ is a cumulative distribution function,

$$
\int_{-M}^{I}(M-Z) d F^{N-1}(Z)<\int_{-M}^{I}(M-Z) \frac{d F^{N-1}(Z)}{F^{N-1}(I)}=E\left(M-I_{N-1}^{*} \mid I\right) .
$$

Consequently,

$$
\int_{-M}^{M}\left(\int_{-M}^{I}(M-Z) d F^{N-1}(Z)\right) d F^{N}(I)<M-E\left(I_{N-1}^{*}\right) .
$$

This inequality and (A38) imply

$$
H<E\left[E^{-1}\left[e^{R^{2} \sigma^{2} Q^{F} I_{N-1}^{*}} \mid I_{N}^{*}\right]\right]\left(M-E\left(I_{N-1}^{*}\right)\right) .
$$

Let us now get back to the f.o.c. for the fragmented market, that is, to Equation (A27). By replacing $H$ by the left-hand side of the last inequality it follows that

$$
E\left[E^{-1}\left[e^{R^{2} \sigma^{2} Q^{F} I_{N-1}^{*}} \mid I_{N}^{*}\right]\right]\left(2 Q^{F}-L-E\left(I_{N-1}^{*}\right)\right)>0,
$$

which implies $Q^{F}>\frac{1}{2}\left(L+E\left(I_{N-1}^{*}\right)\right)$. The combination of this inequality and (A25) shows the result. Q.E.D.

\section{REFERENCES}

Biais, Bruno, 1993, Price formation and equilibrium liquidity in fragmented and centralized markets, Journal of Finance 48, 157-185.

Bloomfield, Robert, and Maureen O'Hara, 1999, Market transparency: Who wins and who loses? The Review of Financial Studies 12, 5-35.

Fleming, Michael, and Eli Remolona, 1999, Price formation and liquidity in the U.S. Treasury market: The response to public information, Journal of Finance 54, 1901-1915.

Flood, Mark D., Ronald Huisman, Kees G. Koedijk, and Ronald J. Mahieu, 1999, Quote disclosure and price discovery in multiple-dealer financial markets, The Review of Financial Studies 12, 37-59.

Frutos, M. Ángeles de, and Carolina Manzano, 2000, Risk aversion, transparency, and market performance, Working Paper 00-48 (19), Universidad Carlos III de Madrid.

Gemmill, Gordon, 1996, Transparency and liquidity: A study of block transactions in the London Stock Exchange, Journal of Finance 51, 1765-1790.

Hansch, Oliver, Narayan Naik, and S. Viswanathan, 1998, Do inventories matter in dealership markets? Evidence from the London Stock Exchange, Journal of Finance 53, 1623-1656.

Ho, Thomas, and Hans Stoll, 1983, The dynamics of dealer markets under competition, Journal of Finance 38, 1053-1074. 
Huang, Chi-fu, and Robert H. Litzenberger, 1988, Foundations for Financial Economics (NorthHolland, New York).

Kimball, A. W., 1951, On dependent tests of significance in the analysis of variance, Annals of Mathematical Statistics 22, 600-602.

Madhavan, Ananth, 1995, Consolidation, fragmentation, and the disclosure of trading information, The Review of Financial Studies 8, 579-603.

Madhavan, Ananth, David Porter, and Daniel Weaver, 1999, Should security markets be transparent, Working paper, University of Southern California.

Maskin, Eric, and John Riley, 2000, Asymmetric auctions, Review of Economic Studies 67, 413-438.

Matthews, Steven, 1987, Comparing auctions for risk-averse buyers: A buyer's point of view, Econometrica 55, 633-646.

Naik, Narayan, Anthony Neuberger, and S. Viswanathan, 1999, Trade disclosure regulation in markets with negotiated trade, The Review of Financial Studies 12, 886-900.

Securities and Exchange Commission, Division of Market Regulation, 1995a, Market 2000: An Examination of Current Equity Market Developments (SEC, Washington, DC).

Securities and Exchange Commission, Division of Market Regulation, 1995b, Release No. 34 36310; File No. S7-30-95 (SEC, Washington, DC).

Securities and Investment Board (SIB), 1994, Regulation of the United Kingdom Equity Markets (SIB, London).

Waehrer, Keith, Ronald M. Harstad, and Michael H. Rothkopf, 1998, Auction form preferences of risk-averse bid takers, Rand Journal of Economics 29, 179-192. 